\title{
Life threatening corpus luteal hemorrhage
}

Wadha Al Ghafri, Vaidyanathan Gowri*, Maha Al- Khaduri and Maryam Al-Shukri

*Correspondence: gowrie61@hotmail.com

Department of Obstetrics and Gynecology, Sultan Qaboos University, Sultanate of Oman.

\begin{abstract}
Ovulation is a physiological event but hemorrhage from corpus luteum is known to occur in reproductive age group women. Life threatening hemorrhage in an unmarried young girl anticoagulated on Warfarin for metallic heart valve is described in this case report. Conservative surgical management in the form ovarian cystectomy was possible in spite of massive hemorrhage. This report also discusses the options of hormonal ovulation suppression in these young girls and their safety.
\end{abstract}

Keywords: Corpus luteum, hemorrhage, ovulation, anticoagulants

\section{Introduction}

Ovulation is a physiological monthly event in women of reproductive age. Corpus luteum hemorrhage may occur spontaneously or often triggered by coitus, trauma, exercise, or vaginal examination [1]. The risk of hemorrhagic complications of ovulation starts on the ovulation day and extends throughout corpus luteal life span, which is 14 days without pregnancy. Its presentation is variable depending on the extent of the hemorrhage but it can be massive requiring surgical intervention and blood transfusion. Patients on anticoagulation are at higher risk for significant severe hemorrhage from ruptured corpus luteum [2].

\section{Case presentation}

A 16 year old girl presented with dull lower abdominal pain of one week duration associated with vomiting and fever on the day of presentation to the hospital. Her last period was two weeks ago. There were no urinary or bowel symptoms. Her history was significant for mitral valve replacement at 15 months of age for mitral valve dysplasia and sub-aortic membranous obstruction. She was anticoagulated with $6 \mathrm{mg}$ of Warfarin daily. She looked sick and in pain. Her temperature was $38.2^{\circ} \mathrm{C}$, pulse 100 beats per minute, and Blood Pressure $110 / 63 \mathrm{mmHg}$. She required $5 \mathrm{~L}$ of Oxygen through facemask to maintain saturation with evidence of crepitations in the base of the left lung. There was a loud first heart sound with a metallic click. Her abdomen was distended with generalized tenderness and infra-umbilical guarding. Her hemoglobin was $6.5 \mathrm{~g} / \mathrm{dl}$, white cell count of $13,000 / \mathrm{dl}$, INR was 8 and pregnancy test was negative. Serum amylase was $60 \mathrm{iu}$. A computerized scan (CT) of the chest showed bilateral consolidation of lower lung lobes. Echocardiography showed normally functioning mitral and aortic valves with no vegetations. There was free fluid in the abdomen likely hemorrhagic, a mass adjacent to the right ovary with cystic areas and fat stranding but not suggestive of abscess. Ultrasound guidedparacentesis of the peritoneal fluid revealed frank blood. A decision for laparotomy was made but due to worsening tachypnea, tachycardia, and desaturation, she was intubated, ventilated, and transferred to intensive care unit. She was supported withblood and blood products like cryoprecipitate and fresh frozen plasma to correct the INR and antibiotics were also started (Meropenam, Amikacin and Vancomycin). Exploratory laparotomy revealed hemoperitoneum of about one litre with normal looking uterus and tubes, bowel, appendix and left ovary. There was fresh bleeding from ruptured corpus luteum cyst of the right ovary and that was controlled by suturing.

\section{Discussion}

Corpus luteum rupture is one of the differential diagnoses of "acute abdomen" in women of reproductive age. Although it can occur at any time of life, it is likely to develop in the early period after menarche [3]. Though there are many case series in the literature on corpus luteal bleeding reported in the literature $[2,4]$ corpus luteal bleed related to prosthetic heart valve was discussed only in a few reports [5]. Most of the earlier reports have resorted to options like salpingooophorectomy in the past or medical management [5]. This case report highlights the difficulties in diagnosing especially if they present with fever, possible differential diagnoses and the possibility of conservative surgery (cystectomy) to preserve fertility.

It is described more from the right ovary as it is believed that the recto-sigmoid colon helps protect the left ovary from trauma [4] or it is due to a higher intraluminal pressure on the right side because of the differences in ovarian vein architecture [1]. The accurate diagnosis depends on the clinical presentation, results of the work-up and index of suspicion. Negative pregnancy test is important to exclude ruptured ectopic pregnancy. This patient was a teenager with a mechanical mitral valve on anticoagulation.

Although the incidence of ovulation bleed or corpus luteum hemorrhage in the general population is not known, 
Ghafri et al. Gynecology 2013,

http://www.hoajonline.com/journals/pdf/2052-6210-1-2.pdf

doi: $10.7243 / 2052-6210-1-2$

the incidence of corpus luteum hemorrhage in teens might be increasing possibly due to sexual intercourse [6]. It also appears that women on anticoagulation tend to suffer more severe hemorrhage [2]. In this population corpus luteum hemorrhage can be fatal in 3\% to $11 \%$ [6] of cases and may recur in nearly $25 \%$ to $31 \%[1,7]$, even when INR is still within or below the therapeutic range [2]. In some cases conservative management is possible if the diagnosis is accurate and patient remains stable. Beside close observation, periodic repeat hematological investigations, analgesia, and correction of coagulation, replacement of blood and blood products and cardiopulmonary support might be required. Surgical intervention might be necessary if other causes of acute abdomen are suspected, if patient is unstable, or if the bleeding fails to settle on conservative management in a reasonable time. Laparotomy approach is the standard in unstable patient, although the role and feasibility of laparoscopy in unstable patient with ruptured ovarian cyst is recently described [8]. Laparoscopy is likely to increase as more surgeons are experienced in such situations. Ovarian electro-coagulation, cystectomy, wedge resection, and ovarian reconstruction are conservative methods to secure hemostasis. Women on anticoagulation tend to require oopherectomy more compared to those not receiving anticoagulation [2]. Fortunately resorting to oopherectomy is becoming less as the conservative surgical approach continues to dominate the trend.

Finding asafe, effective, and acceptable method to inhibit ovulation in women on anticoagulation for mechanical heart valve is a challenge. The challenge can be medical or social. Beside the medical challenges, the social taboo attached to the use of contraceptive methods by unmarried women is a big obstacle in some communities. Those challenges highlight the importance of proper individualized counseling.

The increased risk of venous and arterial thrombosis in women using combined oral contraceptives (COC) in the general population have been extrapolated to those women on anticoagulation despite the lack of strong evidence. Though some experts have recommended the use of low-estrogen containing $\mathrm{COC}$ to prevent corpus luteum hemorrhage in patients who are well anticoagulated [9] World Health Organization, states that combined contraceptives (oral, injectable, patches and rings) are deemed unsuitable for use in women who are currently anticoagulated [10].

Progestin only methods include progestin-only pills, DepoMeroxyprogeserone acetate (DMPA), norethisteroneenantate, levonorgestrel (LNG) or etongesetrel implants and levonorgestrel-Intra-uterine System (LNG- IUS) [10]. Although they are all effective contraceptives; not all are effective ovulation inhibitors. Progestin-only pill like oral desogestrel (Cerazette) consistently inhibits ovulation, whereas norethindrone acetate (Micronor) of $0.35 \mathrm{mg}$ inhibits ovulation only in about $30 \%$ of the times [11]. LNG- IUS exerts their contraceptive effects by local mechanisms on the uterus but they don't inhibit ovulation. Intramuscular injection of DMPA consistently suppresses ovulation [12]. Though loss of bone mineral density and water retention are some of the side effects of DMPA, the former is reversible on stopping the medication and the latter is not a problem in young girls with normal cardiac function. The progestin implants are similar to DMPA in inhibiting ovulation and as far as we know there are no reported concerns at insertion sites like bleeding or hematoma that preclude their use in anticoagulated patients $[13,14]$. GonadotropinReleasing Hormone analogs ( $\mathrm{GnRHa}$ ) are another type of ovulation inhibitors. They induce a psuedomenopause status. Some authors used GnRHa with estrogen add-back therapy in a patient who had undergone previous surgeries for corpus luteum hemorrhage [15]. However, long-term use of GnRHa is undesirable because of its related adverse effects and high cost and was not considered for our patient due to her age.

\section{Conclusion}

Although significant ovulation related ovarian bleeding is rare in healthy women, it carries a considerable risk to women on anticoagulation. It should be prevented by inhibition of ovulation in those women on anticoagulation who suffered a significant bleed. DMPA seems to be safe and effective to suppress ovulation in those women.

\section{Competing interests}

The authors declare that they have no competing interests.

Authors' contributions

Wadha Ghafri- drafted the manuscript and did literature search. Vaidyanathan Gowri edited the manuscript several times and corresponding author Maha Al KhaduriConsultant who managed the patient and reviewed the manuscript. Maryam Al Shukrui- did extensive literature search and contributed to discussion.

Publication history

Received: 13-Mar-2013 Revised: 17-Apr-2013

Re-Revised: 24-Apr-2013 Re-Revised: 25-Apr-2013

Accepted: 27-Apr-2013 Published: 07-May-2013

\section{References}

1. Stenchever M et al.: Comprehensive gynecology. 5-th edition. USA, Mosby, pp 460-461, 2007.

2. Jamal A and Mesdaghinia S: Ruptured corpus luteum cysts and anticoagulant therapy. Int J Gynaecol Obstet 2002, 76:319-20. | Article I PubMed

3. Spinelli C, Di Giacomo M, Mucci N and Massart F: Hemorrhagic corpus luteum cysts: an unusual problem for pediatric surgeons. $J$ Pediatr Adolesc Gynecol 2009, 22:163-7. I Article I PubMed

4. Payne JH, Maclean RM, Hampton KK, Baxter AJ and Makris M: Haemoperitoneum associated with ovulation in women with bleeding disorders: the case for conservative management and the role of the contraceptive pill. Haemophilia 2007, 13:93-7. | Article | PubMed

5. Tresch DD, Halverson G, Blick M and Keelan MH, Jr.: Ovarian (corpus luteum) hemorrhage during anticoagulation therapy. Ann Intern Med 1978, 88:642-6. I Article I PubMed

6. Ho WK, Wang YF, Wu HH, Tsai HD, Chen TH and Chen M: Ruptured corpus luteum with hemoperitoneum: case characteristics and demographic changes over time. Taiwan J Obstet Gynecol 2009, 48:108- 
Ghafri et al. Gynecology 2013,

http://www.hoajonline.com/journals/pdf/2052-6210-1-2.pdf

12. | Article | PubMed

7. Crétel E, Cacoub P, Gompel A, Durand JM and Piette JC: Ovarian hemorrhage with hemoperitoneum leads to complication of oral treatment using indirect anticoagulant administered by the oral route. La Revue de Médecine Interne 2000, 21: 428-434. | Article

8. Hackethal A, lonesi-Pasacica J, Kreis D, Litzlbauer D, Tinneberg HR and Oehmke F: Feasibility of laparoscopic management of acute haemoperitoneum secondary to ruptured ovarian cysts in a haemodynamically unstable patient. Minim Invasive Ther Allied Technol 2011, 20:46-9. | Article | PubMed

9. American College of Obstetricians and Gynecologists: ACOG practice bulletin. No. 73: Use of hormonal contraception in women with coexisting medical conditions. Obstet Gynecol 2006, 107:1453-72. | PubMed

10. World Health Organization: Medical Eligibility Criteria for Contraceptive Use (4th ed.); 2009. I Pdf

11. Rice CF, Killick SR, Dieben T and Coelingh Bennink H: A comparison of the inhibition of ovulation achieved by desogestrel 75 micrograms and levonorgestrel 30 micrograms daily. Hum Reprod 1999, 14:982-5. | Article | PubMed

12. Sonmezer M, Atabekoglu C, Cengiz B, Dokmeci F and Cengiz SD: Depotmedroxyprogesterone acetate in anticoagulated patients with previous hemorrhagic corpus luteum. Eur J Contracept Reprod Health Care 2005, 10:9-14. | Article | PubMed

13. Bennink HJ: The pharmacokinetics and pharmacodynamics of Implanon, a single-rod etonogestrel contraceptive implant. Eur J Contracept Reprod Health Care 2000, 5 Suppl 2:12-20. | PubMed

14. Culwell KR and Curtis KM: Use of contraceptive methods by women with current venous thrombosis on anticoagulant therapy: a systematic review. Contraception 2009, 80:337-45. | Article | PubMed

15. Ulrich $U$ and Rossmanith WG: Management of peritoneal hemorrhage due to follicle rupture under anticoagulation therapy. J Endocrinol Invest 1994, 17:351-3. | Article | PubMed

\section{Citation:}

Ghafri WA, Gowri V, Khaduri MA and Shukri MA: Life threatening corpus luteal hemorrhage. Gynecology 2013, 1:2. http://dx.doi.org/10.7243/2052-6210-1-2 